\title{
ANALISIS PERHITUNGAN PAJAK MINERAL BUKAN LOGAM DAN BATUAN SERTA KONTRIBUSINYA TERHADAP PAD DI KABUPATEN MINAHASA (TAHUN 2013-2017)
}

\author{
Gratia Tita Luntungan $^{1}$, Hendrik Manossoh ${ }^{2}$, Treesje Runtu ${ }^{3}$ \\ 1,2,3 Jurusan Akuntansi, Fakultas Ekonomi dan Bisnis, Universitas Sam Ratulangi, Jl. Kampus Bahu, Manado \\ 95115, Indonesia
}

email : gratiatita@yahoo.com

\begin{abstract}
Tax is the main source of a country that is used by the government to finance expenses in order to achieve prosperity and prosperity. Local taxes and levies are a source of regional original income (PAD), one of the potential taxes, namely the tax on non-metallic minerals and rocks. This study aims to see how the tax on non-metallic minerals and rocks in increasing tax revenues and to determine the contribution of non-metallic and coal mining taxes to regional original income (PAD). The research method used is a qualitative descriptive method. The results of this study note that the average contribution of local taxes to PAD over a period of 5 years is $0.268 \%$, which means that the contribution of local taxes is very lacking and for calculations obtained by the Office of BPP-Retda in Minahasa District through the tax base Predetermined nonmetallic minerals and rocks.
\end{abstract}

Keywords: Taxes of Non-Metallic Minerals and Rocks, Contributions, Local Revenue

\section{PENDAHULUAN}

Indonesia merupakan negara yang tujuannya telah tertera dalam Pembukaan UndangUndang Dasar 1945 alinea ke IV. Berdasarkan tujuan itu, negara memiliki beberapa tugas yaitu rutin dan pembangunan. Dalam menjalankan tugas, negara membutuhkan sumber pembiayaan. Sumber pembiayaan negara antara lain: bantuan luar negeri, hasil bumi, hasil perusahaan - perusahaan milik negara, denda-denda, salah satunya pungutan berupa pajak. Kewajiban pemerintah daerah yaitu pengelolaan pendapatan daerah secara efektif. (Yuliandika 2016:1) "Pendapatan Asli Daerah (PAD) merupakan modal utama untuk mendukung proses pengembangan di daerah sehingga demi kebutuhan rakyat. Salah satu bentuk penerimaan negara yang terbesar yakni dari sektor pajak, dari segi ekonomi pajak merupakan pemindahan sumbernya dari sektor perusahaan ke sektor pemerintah sebaliknya bagi perusahaan, pajak merupakan beban yang akan mengurangi laba bersih. Bagian pajak daerah yang perlu diperhatikan oleh pemerintah yaitu Pajak Mineral Bukan Logam dan Batuan yang terus bertambahnya kebutuhan akan bahan mineral bukan logam dan batuan yang dimanfaatkan sebagai bahan dasar industri dan pembangunan pemukiman di Minahasa." Hal-hal yang termasuk kedalam bagian provinsi ialah pengaturan mengenai Pajak Mineral Bukan Logam dan Batuan. Pajak Mineral Bukan Logam dan Batuan dulunya disebut Galian Golongan C sejak tahun 2009 dalam UU No. 4 Tahun 2009.

Pajak MBLB yaitu kekuatan perolehan daerah Kabupaten Minahasa yang wajib digali secara sebanyak-banyaknya dan menumpas penambang liar atau illegal minning mineral bukan logam dan batuan di Kabupaten Minahasa, penambang liar atau illegal minning sungguh tidak menguntungkan daerah karna selain tidak memiliki persetujuan yang boleh menghancurkan lingkungan, juga tidak melaksanakan penunaian pajak, adanya Perda Nomor 9 Tahun 2010 tentang Pajak MBLB untuk terwujudnya pemungutan Pajak bahan MBLB secara baik dan selarasa dengan peraturan. Kontribusi dalam pajak daerah merupakan suatu yang diberikan dalam jumlah beserta dengan sapek lain untuk tujuan kerugian sendiri atau 
bersama dibandingkan dengan jumlah hasil pendapatan daerah. ( Purnama 2016:2) "Kontribusi dalam Pajak Mineral Bukan Logam dan Batuan yaitu nilai untuk melihat tingkat kontribusi yang dihitung berdasarkan persantase perbandingan realisasi penerimaan Pajak Mineral Bukan Logam dan Batuan dengan realisasi Pendapatan Asli Daerah (PAD)."

\section{TINJAUAN PUSTAKA}

Konsep Akuntansi. Wilson dan Freeman (2015) mengatakan "akuntansi merupakan suatu proses pengelompokkan, pendataan, pelaporan, pengiterprestasian dan penguraian hambatan dari transaksi keuangan dari suatu bisnis atau sistem untuk menyediakan petunjuk kepada yang empunya manajemen dan sudut lain yang memerlukan.

Konsep Pajak. Mardiasmo (2013) Pajak adalah "iuran kepada negara berdasarkan UndangUndang (yang dapat dipaksakan) dengan tidak dapat jasa timbal balik (konsentrasi), yang langsung dapat ditunjukan dan digunakan untuk membayar pengeluaran umum.

Konsep Pajak Mineral Bukan Logam dan Batuan. Berdasarkan (Undang-Undang No 28 Tahun 2009) "Pajak Mineral Bukan Logam dan Batuan merupakan pajak dari proses pengambilan mineral bukan logam dan batuan, yang bersumber dari alam di dalam dan juga di luar bumi untuk digunakan.

Kontribusi. "Kontribusi dalam pajak daerah adalah sejauh mana jumlah dana yang terkumpul dari sektor pajak disuatu daerah dibandingkan dengan jumlah total pendapatan daerah.

Pendapatan Asli Daerah (PAD). "Pendapatan Asli Daerah (PAD) merupakan semua wewenang daerah yang dinyatakan menjadi pelengkap nilai kekayaan murni dalam waktu taksiran tertentu (Undang-Undang No. 32 Tahun 2004 tentang pemerintah daerah).

Penelitian Terdahulu. Pamela (2014) "Efektifitas Penerimaan Pajak Pengambilan dan Pengolahan Mineral Bukan Logam dan Batuan Sebagai Sumber Pendapatan Asli Daerah Kota Tomohon hasil penelitian menunjukkan bahwa proyeksi penerimaan Pajak Mineral Bukan Logam dan Batuan Kota Tomohon sebesar Rp. 67.135.104. Fajar (2015) dengan judul "Mekanisme Pemungutuan Pajak Mineral Bukan Logam dan Batuan dan Kontribusnya Terhadap Pendapatan Daerah Kabupaten Boyolali yang hasil Hasil penelitian ini menunjukan bahwa pajak mineral bukan logam dan batuan tidak banyak berkontribusi terhadap PAD di dinas pendapatan daerah. Wirda (2017) dengan judul "Analisis Penentuan Potensi, Efektifitas dan Kontribusi Penerimaan Pajak Mineral Bukan Logam dan Batuan Hasil menunjukkan bahwa potensi penerimaan pajak mineral bukan logam dan batuan dari tahun 2013 - 2016 mengalami pertumbuhan yang fluktuatif.

\section{METODE PENELITIAN}

Jenis Penelitian. Jenis penelitian yang dipakai dalam penelitian ini adalah penelitian deskriptif kualitatif.

Tempat dan Waktu Penelitian. Tempat yang ditentukan sebagai lokasi penelitian sesuai dengan judul penelitian yaitu pada Badan Pengelola Pajak dan Retribusi Daerah.Waktu penelitian dimulai dari bulan Agustus tahun 2018 sampai dengan selesai.

Jenis, Sumber dan Metode Pengumpulan Data. Data kualitatif adalah data yang disajikan atau dalam bentuk uraian, data tersebut berupa gambaran umum dan sturktur instansi BPP-Retda Kabupaten Minahasa. Sedangkan data kuantitatif adalah tata cara penelitian yang menghasilkan bentuk angka-angka, data tersebut berupa cara perhitungan pajak mineral bukan logam batuan, laporan target dan realisasi pajak daerah pada tahun 20132017 dan laporan target dan realisasi pajak daerah terhadap PAD kabupaten Minahasa. Sumber data dalam penelitian ini yaitu data primer dan data sekunder. Data primer dalam penelitian ini adalah hasil wawancara dengan Kepala Badan Pengelola Pajak dan Retribusi Daerah dan staf yang berkaitan terkait dalam memahami cara perhitungan pajak mineral 
bukan logam dan batuan. Data Sekunder dari penelitian ini adalah dokumentasi. Metode wawancara secara langsung berupa tanya jawab dengan Pimpinan Kantor Badan Pengelola Pajak dan Retribusi Daerah dan staf. Wawancara untuk memperoleh informasi cara perhitungan dan rumus kontribusi pajak mineral bukan logam dan batuan. Studi dokumentasi, metode pengumpulan data dengan cara pengumpulan data dengan menggunakan dokumendokumen dari Kantor Badan Pengelola Pajak dan Retribusi Daerah. Dokumen ini adalah laporan target dan realisasi pajak daerah tahun 2013-2017 dan target dan realisasi terhadap PAD tahun 2013-2017.

Metode dan Proses Analisis. Metode analisis data yang digunakan dalam penelitian ini adalah analisis deskriptif kualitatif. Langkah-langkah yang berkaitan dengan penyusunan pajak daerah adalah:

a. Analisis Perhitungan Pajak Mineral Bukan Logam dan Batuan. Data yang dikumpulkan yaitu data cara perhitungan Pajak Mineral Bukan Logam dan Batuan, yaitu:

Jumlah Produksi x Harga Jual x Tarif Pajak.

b. Analisis Kontribusi. Data yang diperoleh yaitu rumus kontribusi, berupa:

$$
\text { Kontribusi }=\frac{\text { Realisasi Penerimaan }(\text { Pajak MBLB })}{\text { Realisasi Pendapatan Asli Daerah }} \times 100 \%
$$

Untuk mengukur kontribusi, maka digunakan indikator sebagai berikut:

Tabel 1. Klasifikasi Kriteria Kontribusi

\begin{tabular}{lcc}
\hline & Persentase & Kriteria \\
\hline $0,00 \%-10 \%$ & & Sangat Kurang \\
$10,10 \%-20 \%$ & Kurang \\
$20,10 \%-30 \%$ & Sedang \\
$30,10 \%-40 \%$ & Cukup Baik \\
$40,10 \%-50 \%$ & Baik \\
Diatas $50 \%$ & Sangat Baik \\
\hline
\end{tabular}

Sumber : Depdagri, Kepmendagri (Rima Adelina, 2012)

Tabel 1 diatas menunjukkan klasifikasi kriteria kontribusi dimana persentase 0,00-10\% masuk dalam kriteria sangat kurang, 10,10-20\% adalah kurang, 20,10-30\% adalah sedang, $30,10-40 \%$ adalah cukup baik, $40,10-50 \%$ adalah baik dan diatas $50 \%$ adalah sangat baik.

\section{HASIL ANALISIS DAN PEMBAHASAN}

\subsection{Hasil Analisis Perhitungan Pajak Mineral Bukan Logam dan Batuan di} Kabupaten Minahasa

Objek penelitian dalam penelitian ini adalah "Pajak Mineral Bukan Logam dan Batuan yang merupakan pajak yang dikelola oleh Badan Pengelola Pajak dan Retribusi Daerah Kabupaten Minahasa. Pajak Mineral Bukan Logam dan Batuan dahulu dipungut dan diadministrasikan oleh pemerintah pusat, tetapi hasilnya dibagikan lagi kepada masingmasing daerah untuk pembangunan daerah dalam bentuk dana bagi hasil pajak." Perhitungan Pajak MBLB diatur dalam Perda No 1 Tahun 2011 Bab VIII bagian kedua pasal 15 tentang Dasar Pengenaan dan Tarif Pajak Serta Wilayah Pemungutan. Maka dari itu, perhitungan Pajak MBLB dihitung berdasarkan rumus yang telah ditetapkan pemerintah Kabupaten Minahasa yaitu:

\section{Jumlah Produksi x Harga Jual x Tarif Pajak}

Jumlah Produksi yaitu jumlah yang dihasilkan oleh Wajib Pajak yang mengambil atau mengolah Mineral Bukan Logam dan Batuan, Harga Jual yaitu harga yang telah ditetapkan 
oleh Keputusan Gubernur Sulawesi Utara No 159 Tahun 2018 tentang Penetapan Harga dan Patokan Jual Mineral Bukan Logam dan Batuan di Sulawesi Utara dan Tarif Pajak yaitu tarif yang sudah ditetapkan berdasarkan Peraturan Daerah No 1 Tahun 2011 sebesar 20\%.

Target dan Realisasi Pajak Mineral Bukan Logam dan Batuan Kabupaten Minahasa. Berdasarkan tabel 2 di bawah ini menunjukkan bahwa target penerimaan Pajak Mineral Bukan Logam dan Batuan Kabupaten Minahasa tahun 2013 Rp2.000.000.000,00 dan realisasi Rp2.596.743.000,00. Pada tahun 2014 target Rp2.300.000.000,00 dan realisasi Rp3.644.246.400,00. Tahun 2015 target Rp4.000.000.000,00 dan realisasi Rp4.401.762.300,00. Tahun 2016 target $\mathrm{Rp4.000.000.000,00} \mathrm{dan} \mathrm{realisasi}$ Rp4.584.743.400,00. Dan di tahun 2017 target Rp4.250.000.000,00 dan realisasi Rp4.322.630.282,00.

Tabel 2. Target dan Realisasi Pajak Mineral Bukan Logam dan Batuan Kabupaten Minahasa Tahun 2013-2017

\begin{tabular}{ccr}
\hline Tahun & Target (Rp) & \multicolumn{1}{c}{ Realisasi (Rp) } \\
\hline 2013 & $2.000 .000 .000,00$ & $2.596 .743 .000,00$ \\
2014 & $2.300 .000 .000,00$ & $3.644 .246 .400,00$ \\
2015 & $4.000 .000 .000,00$ & $4.401 .762 .300,00$ \\
2016 & $4.000 .000 .000,00$ & $4.458 .743 .400,00$ \\
2017 & $4.250 .000 .000,00$ & $4.322 .630 .282,00$ \\
\hline
\end{tabular}

Sumber : Data Badan Pengelola Pajak dan Retribusi Daerah Kabupaten Minahasa

Kontribusi Pajak Mineral Bukan Logam dan Batuan Terhadap Pendapatan Asli Daerah Kabupaten Minahasa. Berdasarkan Tabel 3 di bawah ini menunjukkan kontribusi dari Pajak MBLB terhadap PAD Kabupaten Minahasa tahun 2013-2017. Pada tahun 2013 realisasi Pajak Mineral Bukan Logam dan Batuan Rp2.596.743.000,00 sedangkan realisasi dari Pendapatan Asli Daerah sebesar Rp31.964.854.060,00. Tahun 2014 realisasi Pajak Mineral Bukan Logam dan Batuan Rp3.644.246.400,00 dan realisasi Pendapatan Asli Daerah Rp58.778.368.154,00. Tahun 2015 realisasi Pajak Mineral Bukan Logam dan Batuan Rp4.401.762.300,00 dan realisasi Pendapatan Asli Daerah Rp73.125.539.559,00. Tahun 2016 realisasi dari Pajak Mineral Bukan Logam dan Batuan sebesar Rp4.584.743.400,00 dan realisasi dari Pendapatan Asli Daerah sebesar Rp77.933.004,819,00. Dibandikang dengan tahun 2017 realisasi Pajak mineral Bukan Logan dan Batuan sebesar Rp4.322.630.282,00 dan realisasi dari Pendapatan Asli Daerah sebesar Rp112.621.999.187,00.

Tabel 3. Realisasi Pajak Mineral Bukan Logam dan Batuan terhadap Pendapatan Asli Daerah Kabupaten Minahasa Tahun 2013-2017

\begin{tabular}{ccr}
\hline Tahun & $\begin{array}{c}\text { Realisasi Pajak } \\
\text { MBLB (Rp) }\end{array}$ & $\begin{array}{c}\text { Realisasi PAD } \\
\text { (Rp) }\end{array}$ \\
\hline 2013 & $2.596 .743 .000,00$ & $31.964 .854 .060,00$ \\
2014 & $3.644 .246 .400,00$ & $58.778 .368 .154,00$ \\
2015 & $4.401 .762 .300,00$ & $73.125 .539 .559,00$ \\
2016 & $4.584 .743 .400,00$ & $77.933 .004 .819,00$ \\
2017 & $4.322 .630 .282,00$ & $112.621 .999 .187,00$ \\
\hline
\end{tabular}

Sumber : Data BPP-Retda Daerah Kabupaten Minahasa

\subsection{Pembahasan}

Prosedur Perhitungan Pajak Mineral Bukan Logam dan Batuan di Kabupaten Minahasa. Berdasarkan penelitian yang dilakukan, maka dapat diketahui bahwa prosedur Perhitungan dari Pajak Mineral Bukan Logam dan Batuan di Kabupaten Minahasa ini 
dilakukan berdasarkan Peraturan Daerah (Perda) Kabupaten Minahasa Nomor 1 Tahun 2011 tentang Sistem Prosedur dan Pengenaan Pajak MBLB. Ditetapkan bahwa:

1. Badan Pengelola Pajak dan Retribusi Daerah (BPP-Retda) menyampaikan Surat Pemberitahuan Pajak Daerah (SPTPD) Pajak Mineral Bukan Logam dan Batuan tersebut berdasarkan laporan produksi pengambilan Mineral Bukan Logam dan Batuan (MBLM) kepada Wajib Pajak.

2. Surat Pemberitahuan Pajak Daerah (SPTPD) tersebut disampaika Wajib Pajak kepada Badan Pengelola Pajak dan Retribusi Daerah (BPP-Retda) beserta bukti pembayaran sebelum jatuh tempoh yakni tanggal 10 bulan berjalan untuk masa pajak bulan sebelumnya.

3. Badan Pengelola Pajak dan Retribusi Daerah (BPP-Retda) memverivikasi apakah bukti setoran cocok dengan Surat Pemberitahuan Pajak Daerah (SPTPD) dan laporan produksi, kalau tidak cocok maka dikeluarkan SKPD atau kurang bayar atau SKPD Lebih Bayar.

Kontribusi Pajak Mineral Bukan Logam dan Batuan Terhadap Pendapatatan Asli Daerah Kabupaten Minahasa. Berdasarkan Tabel 4 di bawah ini maka dapat dilihat bahwa kontribusi Pajak MBLB terhadap Pendapatan Asli Daerah Kabupaten Minahasa ratarata dari tahun 2013-2017 adalah sebesar 0,268\%. Jika berdasarkan kriteria atau klasifikasi maka kontribusi dari Pajak MBLB terhadap PAD Kabupaten Minahasa tahun 2013-2017 penilaiannya adalah Sangat Kurang. Berikut perhitungan kontribusi Pajak MBLB terhadap PAD dari tahun 2013-2017:

Tahun 2013 :

$$
\text { Kontribusi }=\frac{2 \cdot 569.743 .000,00}{31.964 .854 .060,00} \times 100 \%=0,082 \%
$$

Tahun 2014 :

$$
\text { Kontribusi }=\frac{3 \cdot 644 \cdot 246.400,00}{58.778 .368 .154,00} \times 100 \%=0,061 \%
$$

Tahun 2015:

$$
\text { Kontribusi }=\frac{4 \cdot 401 \cdot 762 \cdot 300,00}{73 \cdot 125 \cdot 539 \cdot 559,00} \times 100 \%=0,060 \%
$$

Tahun 2016:

$$
\text { Kontribusi }=\frac{4 \cdot 584 \cdot 743 \cdot 400,00}{77 \cdot 933 \cdot 004 \cdot 819,00} \times 100 \%=0,058 \%
$$

Tahun 2017:

$$
\text { Kontribusi }=\frac{4 \cdot 322 \cdot 630 \cdot 282,00}{112 \cdot 621 \cdot 999 \cdot 187,00} \times 100 \%=0,038 \%
$$


Tabel 4. Kontribusi Pajak Mineral Bukan Logam dan Batuan terhadap Pendapatan Asli Daerah Kabupaten Minahasa Tahun 2013-2017

\begin{tabular}{ccrrr}
\hline Tahun & $\begin{array}{c}\text { Realisasi Pajak } \\
\text { MBLB }(\mathbf{R p})\end{array}$ & Realisasi PAD (Rp) & $\begin{array}{r}\text { Persentase } \\
(\mathbf{\%})\end{array}$ & Kriteria \\
\hline 2013 & $2.596 .743 .000,00$ & $31.964 .854 .060,00$ & $0,082 \%$ & Sangat Kurang \\
2014 & $3.644 .246 .400,00$ & $58.778 .368 .154,00$ & $0,061 \%$ & Sangat Kurang \\
2015 & $4.401 .762 .300,00$ & $73.125 .539 .559,00$ & $0,060 \%$ & Sangat Kurang \\
2016 & $4.584 .743 .400,00$ & $77.933 .004 .819,00$ & $0,058 \%$ & Sangat Kurang \\
2017 & $4.322 .630 .282,00$ & $112.621 .999 .187,00$ & $0,038 \%$ & Sangat Kurang \\
& Rata-rata & & $0,268 \%$ & Sangat Kurang \\
\hline
\end{tabular}

Sumber : Data Olahan Tahun 2018

Dapat dilihat dari tabel 4 bahwa kontribusi Pajak Mineral Bukan Logam dan Batuan terhadap Pendapatan Asli Daerah Kabupaten Minahasa pada tahun 2013-2017 semakin menurun kontribusinya. Dimana kontribusi Pajak Mineral Bukan Logam dan Batuan terhadap Pendapatan Asli Daerah Kabupaten Minahasa pada tahun 2013 hanya sebesar Rp2.596.743.000,00 atau hanya pada persentase 0,082\% (Sangat Kurang). Tahun 2014 Rp3.644.246.400,00 atau pada persentase 0,061\% (Sangat Kurang), Tahun 2015 Rp4.401.762.300,00 atau persentase 0,061\% (Sangat Kurang), dan pada tahun 2016 Rp4.584.743.400,00 atau pada presentase 0,058\% (Sangat Kurang) dan pada tahun 2017 Rp4.322.630.282,00 atau hanya pada persentase 0,038\% dan masih dalam klasifikasi (Sangat Kurang). Hal ini menunjukkan bahwa kontribusi Pajak Mineral Bukan Logam dan Batuan di Kabupaten Minahasa masih sangat kurang, maka perlu adanya peran dari Pemerintah Kabupaten Minahasa untuk lebih mengoptimalkan pemungutan terhadap Pajak Mineral Bukan Logam dan Batuan sehingga dapat memberikan kontribusi yang lebih meningkat di tahun selanjutnya.

Selain itu banyaknya data yang tidak akurat dan tidak sesuai dengan kondisi di lapangan yang sebenarnya dan masih banyak pula yang belum memiliki bahkan tidak suka mengurus ijin usaha sehingga penerimaan kurang optimal dan kurangnya kesadaran dari wajib pajak dalam membayar Pajak Mineral Bukan Logam dan Batuan, hal ini juga menjadi faktor penghambat untuk meningkatkan penerimaan Pajak Mineral Bukan Logam dan Batuan. Dengan adanya kerjasama dengan pihak-pihak yang terkait dalam pelaksanaan pemungutan dan pengelolaan Pajak Mineral Bukan Logam dan Batuan diharapkan mampu mengoptimalkan kontribusi Pajak Mineral Bukan Logam dan Batuan terhadap Pendapatan Asli Daerah Kabupaten Minahasa.

\section{KESIMPULAN DAN SARAN}

\subsection{Kesimpulan}

Berdasarkan hasil penelitian dan pembahasan sebelumnya, maka dapat ditarik kesimpulan sebagai berikut:

1. Perhitungan Pajak MBLB di Kabupaten Minahasa dihitung berdasarkan Peraturan Daerah (Perda) Nomor 1 Tahun 2011 Bab VIII bagian kedua pasal 15 tentang Dasar Pengenaan dan Tarif Pajak serta Wilayah Pemungutan dengan tarif 20\% untuk Pajak MBLB. Untuk perhitungan sudah dihitung sesuai rumus yang ditetapkan pemerintah daerah yang berlaku akan tetapi saat dalam perhitungan masih ada kesalahan yang terjadi.

2. Kontribusi dalam penerimaan Pajak MBLB terhadap PAD Kabupaten Minahasa tahun 2013-2017 dengan rata-rata hanya sebesar 0,268\%. Jika berdasarkan kriteria atau klasifikasi maka kontribusi dari Pajak Mineral Bukan Logam dan Batuan terhadap Pendapatan Asli Daerah Kabupaten Minahasa penilaiannya adalah sangat kurang bahkan sangat memperihatinkan. Dengan artian bahwa Pemerintah Kabupaten Minahasa kurang 
optimal dalam pengelolaan Pajak MBLB sebagai sumber pendapatan daerah serta kurangnya kesadaran dari wajib pajak untuk membayar pajak dan masih banyak wajib pajak yang belum dan tidak mau mengurus ijin usaha Mineral Bukan Logam dan Batuan yang mereka miliki.

\subsection{Saran}

Berdasarkan hasil penelitian dan pembahasan serta kesimpulan tersebut, maka penulis memberikan saran antara lain:

1. Sebaiknya Pemerintah Kabupaten Minahasa melakukan penyuluhan yang lebih intensif dan secara berkala kepada wajib pajak dan masyarakat tentang pentingnya membayar pajak khususnya Pajak Mineral Bukan Logam dan Batuan karena secara tidak langsung realisasi dari pajak akan sangat bermanfaat bagi masyarakat nantinya serta menjelaskan kepada mereka bahwa dana yang dipungut itu digunakan untuk membantu kepentingan daerah dengan meningkatkan pembangunan secara umum, dengan begitu masyarakat menjadi termotivasi untuk membayar pajak sehingga kontribusi Pajak Mineral Bukan Logam dan Batuan terhadap Pendapatan Asli Daerah Kabupaten Minahasa lebih meningkat.

2. Pemerintah Kabupaten Minahasa dalam hal ini kantor BPP-Retda harus lebih teliti saat dalam menghitung pajak daerah karena di kantor ini masih menghitung secara manual agar tidak ada masalah dan kekeliruan dalam proses menghitung.

\section{DAFTAR PUSTAKA}

Fajar. 2015. Mekanisme Pemungutan Pajak Mineral Non Logam dan Batuan dan Kontribusinya Terhadap Pendapatan Daerah Kabupaten Boyolali. Skripsi.

Hendra. 2014. Pengertian Akuntansi. Jakarta : Akuntansi Manajemen.

Mardiasmo. 2013. Perpajakan (edisi revisi 2013). Yogyakarta : CV. Andi Offsest.

Purnama. 2016. Optimalisasi Pemungutan Pajak Mineral Non Logam dan Batuan Dalam Rangka Peningkatan PAD Kabupaten Tanah Bumbu. Skripsi.

Simamora. 2013. Pengantar Akuntansi II. Salemba Empat. Jakarta.

Undang-Undang Republik Indonesia Nomor 28 Tahun 2009 Pajak Daerah dan Retribusi Daerah. 18 Agustus 2009. Lembaran Negara Republik Indonesia Nomor 3312. Jakarta.

Undang-Undang Republik Indonesia Nomor 32 Tahun 2014 Pemerintahan Daerah.

Wirda. 2017. Analisis Penentuan Potensi, Efektifitas, dan Kontribusi Penerimaan Pajak Mineral Bukan Logam dan Batuan. Skripsi.

Wilson V, Freeman S dan Freeman J. 2015. Teori Akuntansi. PT Gramedia Pustaka Utama.

Yuliandika. 2016. Mekanisme Perhitungan, Penetapan, Penyetoran, Pelaporan Pajak Mineral Bukan Logam dan Batuan Pada Dinas Pendapatan Daerah Kabupaten Banyuwangi. Skripsi. 